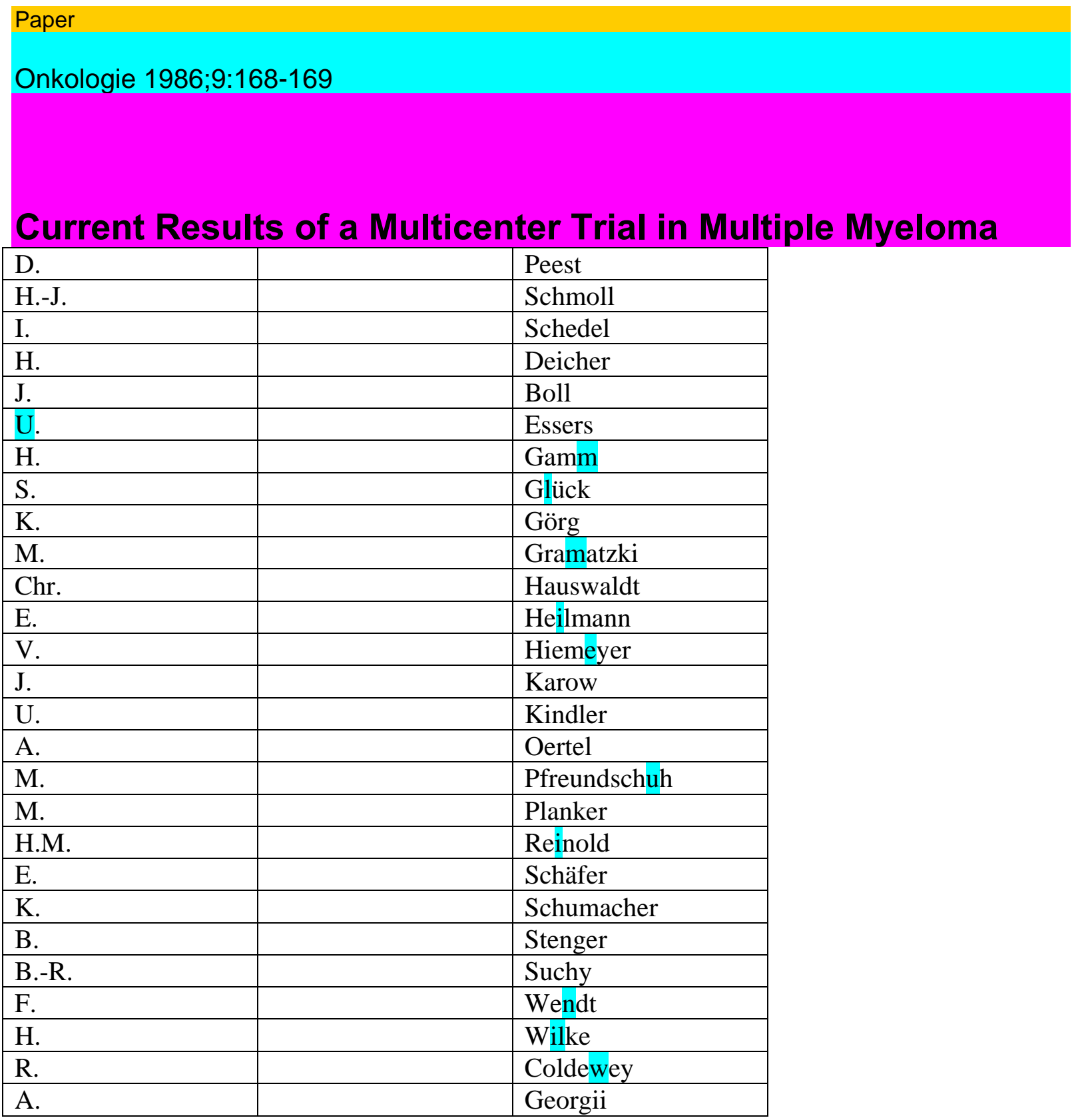

German Myeloma Treatment Group, Medizinische Hochschule Hannover

Key Words

Multiple myeloma

Randomized trial

Maintenance therapy

Summary

257 untreated myeloma patients (stage II and III) were studied in a multicenter trial. The patients were randomized and received MP or VCMP therapy. No differences in remission rate could be found in both therapy arms. After successful remission induction those patients without maintenance therapy relapsed significantly earlier than those patients receiving maintenance therapy. In pilot studies an etoposide therapy was found ineffective and a multidrug therapy (VBAMDex) could induce high remission rates in high risk and pretreated patients. 
Request for reprints to: Dr. med. D. Peest, Abt. Immunologie und Transfusionsmedizin, Zentrum Innere Medizin und Dermatologie, Med. Hochschule Hannover, Konstanty-Gutschow-Straße 8, D-3000 Hannover 61

Zusammenfassung und Schlüsselwörter

In einer multizentrischen Therapiestudie beim multiplen Myelom wurden 257 vorher unbehandelte Patienten (Stadium II und III) untersucht. Eine Therapie mit MP wurde randomisiert gegen eine VCMP-Therapie untersucht. Dabei ließen sich keine unterschied-lichen Remissionsraten in beiden Therapiearmen feststellen. Nach erfolgreicher Induktionstherapie trat bei Patienten ohne Erhaltungs-therapie signifikant früher als bei Patienten mit Erhaltungstherapie ein Rezidiv auf. Im Rahmen von Pilotstudien wurde eine Etoposid-Monotherapie erfolglos versucht und eine Fünffachkombination (VBAMDex) getestet, die sich sogar bei Patienten mit hoher Tumor-zellmasse und Patienten mit multipler Vortherapie als sehr wirksam erwies. Multiples Myelom - Randomisierte Studie - Erhaltungstherapie

Prospective Randomized Trial in Stage II and III Multiple Myeloma: MP Versus VCMP 257 untreated myeloma patients (stages II and III) were randomized into two treatment groups: group 1 treated with melphalan $8 \mathrm{mg} / \mathrm{m} 2$ p.o. plus prednisone $60 \mathrm{mg} / \mathrm{m} 2$ p.o. d. $1-4 \mathrm{Q}$ four weeks [1] and group 2 treated with vincristine $1 \mathrm{mg}$ i.v. d. 1, cyclophosphamide $100 \mathrm{mg} / \mathrm{m} 2$ p.o., melphalan $5 \mathrm{mg} / \mathrm{m} 2$ p.o., and prednisone $60 \mathrm{mg} / \mathrm{m} 2$ p.o. d. $1-4$ Q four weeks [2]. Data from 171 patients were available after induction therapy (6 cycles). The clinical course was compared with the tumor mass change calculated by the method of Salmon and Wampler [3] and a good correlation could be found. The effect of both therapy schemes was equal in both groups of patients (64\% complete and partial remission, $21 \%$ no change, $15 \%$ tumor progress). No differences in remission rates were observed between stage II or stage III patients. Patients with remission were randomized into no maintenance, or maintenance therapy consisting of identical chemotherapy cycles Q eight weeks. Data from 52 patients could be evaluated. Patients without maintenance therapy relapsed significantly more frequently than patients receiving maintenance therapy, but the influence of early relapse on patient's life time remains to be determined. dexamethasone $25 \mathrm{mg} / \mathrm{m} 2$ i.v. d. 1-4, 15-18, 29-32, 43-46, Q eight weeks. 10 patients (7 stage III patients) were untreated; 3 patients were pretreated with one and 7 patients with more than one chemotherapy protocol. 18 patients were IgG or IgA myelomas and their change in tumor mass was calculated using the method of Salmon and Wampler [3]. One Bence Jones myeloma and one patient with a nonsecretory myeloma were judged by radiological and clinical data. The effect of the combination was evaluated after at least one complete cycle of chemotherapy. 7 patients reached a partial remission (25-75 \% reduction of tumor mass) and 11 patients a complete remission (more than $75 \%$ reduction of tumor mass) under this chemotherapy. No change of tumor mass was observed in two patients; progress did not occur. Hematotoxicity requiring dose reduction has been seen in 10 patients. We conclude that VBAMDex is a very effective combination both for untreated and for pretreated high risk myeloma patients. Pilot Study Etoposide Monotherapy

Thirteen myeloma patients were treated in a pilot study with etoposide $120 \mathrm{mg} / \mathrm{m} 2$ i.v. d. 1,2 and 3, Q three weeks. 10 patients were pretreated with one, 3 patients with more than one chemotherapy protocol. Nine of these patients were IgG or IgA myelomas and their change in tumor mass was calculat-

\section{Pilot Study VBAMDex}

Twenty myeloma patients were treated in a pilot study with vincristine $\mathrm{lmg} / \mathrm{m} 2$, adriamycin 15mg/m2, and melphalan 7mg/m2 i.v. d. 1, 15, 29, 43; BCNU 40mg/m2 i.v. d. 1, and 
1 Supported by the Bundesministerium für Forschung und Technologie 01 ZW 010 Peest et al.: Current Results of a Multicenter Trial in Multiple Myeloma

169

ed using the method of Salmon and Wampler [3]. Four Bence Jones myelomas were judged using radiological and clinical data. The effect of etoposide therapy was evaluated after at least three cycles of chemotherapy. The tumor progressed in 8 patients, 5 patients showed no change in tumor mass. No remission was observed. These data show that etoposide as a single agent is ineffective, at least in pretreated myeloma patients.

References

1 Alexanian, R. et al.: Treatment for multiple myeloma. JAMA 208: 1680 (1969).

Alexanian , R. et al.: Chemoimmunotherapy for multiple myeloma. Cancer 47: 1923 (1981).

Salmon, S. E.; Wampler, S. E.: Multiple myeloma: Quantitative staging and assessment of response with a programmable pocket calculator. Blood 49: 379 (1977). 